\title{
Production of Aluminum 6063 Metal Matrix Composite with 12\% Magnesium Oxide and 5\% Graphite and its Machinability Studies using Micro Electrochemical Machining
}

\author{
Babu $\mathrm{B}^{1, *}$, Sabarinathan $\mathrm{C}^{2}$ and Dharmalingam $\mathrm{S}^{3}$ \\ ${ }^{1}$ Department of Mechanical Engineering, Rathinam Technical Campus, Coimbatore, India 641021. \\ ${ }^{2}$ Professor, Department of Mechanical Engineering, Hindusthan College of Engineering and Technology, Coimbatore, India \\ 641032 \\ ${ }^{3}$ Principal, TKS Polytechnic College, Theni, India 625534
}

Corresponding Author Email: babumech874@gmail.com

\begin{abstract}
Hybrid Aluminum Metal Matrix Composites (AMMCs) are finding application in aerospace and automobile industries for its light weight. In this research hybrid AMMCs with $12 \%$ magnesium oxide $(\mathrm{MgO})$ and $5 \%$ graphite $(\mathrm{Gr})$ were fabricated and mechanical properties were studied. The compressive strength, bending stress frictional force, impact strength are found to be $292.94 \mathrm{~N} . \mathrm{mm}^{-2}, 1.31 \mathrm{~N} . \mathrm{mm}^{-2}, 11.3 \mathrm{~N}$ (maximum) $\mathrm{J}_{\mathrm{m}} \mathrm{m}^{-2}=0.4 \times 10^{5}$ respectively. Moreover the highest hardness values are obtained during Brinell and Rockwell testing's 127.23 BHN, 59 HRB respectively. Machinability studies using micro electrochemical machining (micro ECM) is performed on the hybrid AMMCs by varying the voltage, electrolyte concentration, duty cycle and electrolyte temperature. L9 Orthogonal array (OA) is conducted and the experimental results are analyzed using the Technique for Order of Preference by Similarity to Ideal Solution (TOPSIS) method. Based on the TOPSIS analysis the optimal combination for the higher MRR and lesser OC is $9 \mathrm{~V}, 25 \mathrm{gm} . \mathrm{L}^{-1}, 80 \%$ duty cycle and $35^{\circ} \mathrm{C}$ electrolyte temperature $\left(\mathrm{A}_{2} \mathrm{~B}_{2} \mathrm{C}_{3} \mathrm{D}_{1}\right)$. Analysis of Variance (ANOVA) shows that the duty cycle is the most significant factor followed by voltage and electrolyte temperature for higher material removal rate (MRR) and lower overcut (OC).
\end{abstract}

Keywords: Metal Matrix Composites, Mechanical properties, micro ECM, ANOVA, Material removal rate, overcut Received: Februay-28-2020, Accepted: April-20-2020, https://doi.org/10.14447/jnmes.v23i2.a06

\section{INTRODUCTION}

The structural and non-structural applications use aluminum-based metal matrix composites (AMMCs) for its advantage namely higher specific strength and modulus [1]. Research on production of hybrid AMMCs is performed by many researchers, Reddy et al., [1] have developed and tested aluminium 6061-silicon carbide, boron carbide MMCs. The tensile, flexural, hardness and impact tests were performed and results shows that the hybrid composites had better properties than pure aluminum. Inegbenebor et al., [2] have used twostep mixing method of stir casting technique for production of aluminum (99.66 \% C.P) and $\mathrm{SiC}$ (320 and 1200 grits). Reinforced aluminum silicon carbide showed an increase in Young's modulus (E) and marginal reduction of electrical conductivity. Arunachalam et al., [3] have used stir squeeze casting for production of MMCs and optimized the production process using Taguchi Grey method. Narayan et al., [4] have studied the tensile, impact and hardness of the hot forged aluminium metal matrix composites. The hardness and ultimate tensile strength of carbide reinforced AMMCs were found to be higher for water-cooled compared to furnacecooled technique for direct sinter-forged cooling. Subbarao et al., [5] have studied mechanical properties like hardness, tensile strength, yield strength, $\%$ of elongation of AA6061 matrix with Boron carbide $\left(\mathrm{B}_{4} \mathrm{C}\right)$ particles. The mechanical properties found to increase with increase in wt. \% of the reinforcement up to $4 \% \mathrm{~B}_{4} \mathrm{C}$. Munisamy et al., [6] studied effect of zircon sand and boron carbide on the mechanical properties of Al6061. The mechanical testing of AMMCs shows that the addition of zircon and $\mathrm{B}_{4} \mathrm{C}$ improves the hardness, impact and flexural strength. The suitable application of AMMCs depends on the machining methods. The use of conventional machining methods for processing of AMMCs induce poor quality and residual stress on the products, on other way the use of non-conventional machining technique overcomes the difficulties of the former method [7]. Among the various existing methods, micro ECM is found suitable for machining AMMCs [8]. Recently researchers are working on machining of AMMCs using micro ECM. Maniraj et al., [9] have used micro ECM to machine AMMCs and reported that the heat electrode has significant effect on machining rate and accuracy. They have also optimized the micro ECM process parameters using TOPSIS method and percentage reinforcement of ground-granulated blast furnace slag has the significant effect on the machining speed and accuracy [10]. Prakash et al., [11] have analyzed the micro ECM performance using Teaching-Learning-Based Optimization (TLBO) algorithm and RSM method on AA7075 reinforced with nano silicon carbide particles and the results of these analysis are similar. Sathishkumar et al., [12] have fabricated the Al6061+ (6wt \% SiC + 4wt \% Gr) composites using stir casting process. The use of stir casting method improves the ductility and strength of this material when combined with SiC. Moreover they machined AMMCs using electrochemical machining parameters using $\mathrm{L}_{27} \mathrm{OA}$ experimental design and optimized the MRR and OC. Hynes et al., [13] critically reviewed the research work on ECM of AMMCs. They reported that, an increase of voltage, tool feed rate, electrolyte concentration, percentage reinforcement and 
Babu. B et al. / J. New Mat. Electrochem. Systems

flow rate significantly influence the MRR. Jayaganthan et al., [14] studied the influence of micro ECM process parameters on magnesium based hybrid MMC through Taguchi approach. ANOVA results shows that the applied voltage is a major influencing parameter to affects the MRR and surface roughness of the developed MMC. Rajan et al., [15] have investigated the effect of ECM process on AMMCs reinforced with varying percentage of $\mathrm{B}_{4} \mathrm{C}$ using the induction heated electrolyte. The use of induction heated electrolyte governs the machining rate and accuracy. Kalra et al., [16] have machined micro-hole on stir-cast hybrid aluminum/(alumina + silicon carbide + carbon particulates) metal matrix composite using micro ECM. The optimal process parameter combination for high machining rate with low taper $\mathrm{OC}, \mathrm{OC}$, and micro spark affected zone is $1.5 \mathrm{~A}, 13 \mathrm{~V}, 10 \mu \mathrm{s}$ pulse-on time, $10 \mu \mathrm{s}$ pulseoff time, $15 \mathrm{~g} / \mathrm{L}$ electrolyte concentration, and $0.2 \mathrm{~L} / \mathrm{min}$ electrolyte flow rate. Rajan et al. [17] have machined Al7075 using ECM and studied the effect of electrolyte temperature on depth of the micro-hole. The temperature of the electrolyte shows significant effect on the ECM. Shanian and Savadogo [18] have applied multiple-criteria decision analysis method namely TOPSIS for resolving the material selection problem of metallic bipolar plates for polymer electrolyte fuel cell. They reported that the TOPSIS is a potential method for solving the material selection problem.

It evident from the above literatures that production and mechanical properties of MMCs are studied by the researchers and machinability studies on hybrid AMMCs using micro ECM is sparse. Hence in this research the hybrid AMMCs is fabricated using aluminium 6063 reinforced with $12 \%$ magnesium oxide $\left(\mathrm{MgO}_{2}\right)$ and $5 \%$ graphite $(\mathrm{Gr})$. The hybrid AMMCs developed is subjected to the various tests like impact, bending, hardness and wear and the results are obtained. Moreover to study the machinability of the hybrid AMMCs in micro ECM, the $\mathrm{L}_{9}$ Orthogonal array(OA) design of experiments is used to drill blind micro-hole by varying the voltage, electrolyte concentration, duty cycle and electrolyte temperature. The aim of this work is to use the micro ECM setup for conducting the experiments. The setup consists of pulsed power supply, machining chamber, electrode and electrolyte supply system and electrolyte heating unit. Then, the TOPSIS and ANOVA methods are used to analyse the results of the experiments and determine similarities which may form data that exist on them. Based on the TOPSIS and ANOVA the electrical parameter shows the most significant contribution for higher MRR and lower OC.

\section{EXPERIMENTAL SETUP}

The hybrid AMMCs is developed using magnesium oxide and graphite as reinforcement on aluminium matrix. The ratio of these materials is aluminum 6063 with $83 \%$, magnesium oxide with $12 \%$ \& graphite with $5 \%$. Argon gas plays a major role in casting process from beginning to end of this process. The hybrid AMMCs is made up of stir casting process and 600 gm of aluminum pure metal is heated upto $720^{\circ} \mathrm{C}$ in resistance furnace. The reinforcement is preheated upto $300^{\circ} \mathrm{C}$ for time duration to reduce the moisture. The stirring was maintained between 5 to $7 \mathrm{~min}$ at an impeller speed of $200 \mathrm{rpm}$. After melting, the molten metal is poured into the prepared die to make the required workpiece. Manganese, calcium silicate and aluminum are added into the furnace while heating to protect
AMMCs from cracking. The hybrid AMMCs is annealed to improve the strength of the composite material and finished by fettling process. The fabricated hybrid MMCs then cut to the ASTM standards for mechanical testing. ASTM E9-09 and ASTM E855 - 08 standard is followed for the compression test and bending test respectively. ASTM E23-18 is standard test methods for notched bar impact testing of specimen. A ball indenter of diameter $1.588 \mathrm{~mm}\left(1 / 16^{\prime}\right)$ and load of $100 \mathrm{kgf}$ are applied for $15 \mathrm{~s}$ in the Rockwell hardness tester using the Bscale. Hardness readings were taken at different points on each specimen to obtain a representative average value. ASTM E18-20 standard test method is used for Rockwell hardness testing. A Brinell hardness with ball indenter of diameter $10 \mathrm{~mm}$ and load of $500 \mathrm{kgf}$ is applied to known the Brinell hardness number. Wear tests were carried out in accordance with ASTM G99 on samples with a diameter of $10 \mathrm{~mm}$ and height of $30 \mathrm{~mm}$. The load of $3 \mathrm{~kg}$, speed of $500 \mathrm{rpm}$ is applied for 300 sec. Surface is prepared using fine sandpaper and alcohol washing. A pin-on-disc experiment is conducted in a DUCOM make.

The fabricated hybrid AMMC specimen is machined using micro ECM with various input parameters such as voltage, electrolyte concentration, duty cycle and temperature of the electrolyte on MRR and OC. L $_{9} \mathrm{OA}$ experiments were conducted and process parameters and levels are presented in the Table 1 and results of the experiments are presented in the Table 2 [15]. The MRR is calculated by subtracting the weight of the material before and after machining with respect to time. The diameter $\mathrm{OC}$ is calculated by subtracting the micro-hole diameter from the diameter of the tool electrode of $500 \mu \mathrm{m}$. The thickness of the work piece is $1.5 \mathrm{~mm}$. The sodium nitrate $\left(\mathrm{NaNO}_{3}\right)$ electrolyte is prepared by mixing the required amount of salt with one litre of distilled water. The electrolyte is heated using immersion water mini heater $(250 \mathrm{~W})$ and temperature of the electrolyte is noted using the non-contact temperature detector. The TOPSIS and ANOVA methods are used to analysis the results of the experiments. The micro ECM setup is used for conducting the experiments. The setup consists of pulsed power supply, machining chamber, electrode and electrolyte supply system and electrolyte heating unit.

Table 1. Factors and levels

\begin{tabular}{|l|c|c|c|c|}
\hline \multicolumn{1}{|c|}{ Factors } & Notation & $\begin{array}{c}\text { Level } \\
\mathbf{1}\end{array}$ & $\begin{array}{c}\text { Level } \\
\mathbf{2}\end{array}$ & $\begin{array}{c}\text { Level } \\
\mathbf{3}\end{array}$ \\
\hline Voltage (V) & $\mathrm{A}$ & 7 & 9 & 11 \\
\hline $\begin{array}{l}\text { Electrolyte } \\
\text { concentration }\left(\mathrm{gm} . \mathrm{L}^{-1}\right)\end{array}$ & $\mathrm{B}$ & 15 & 25 & 35 \\
\hline Duty cycle $(\%)$ & $\mathrm{C}$ & 50 & 65 & 80 \\
\hline $\begin{array}{l}\text { Electrolyte } \\
\text { temperature }\left({ }^{\circ} \mathrm{C}\right)\end{array}$ & $\mathrm{D}$ & 35 & 38 & 40 \\
\hline
\end{tabular}

Table 2. $\mathrm{L}_{9} \mathrm{OA}$ and responses

\begin{tabular}{|c|c|c|c|c|c|c|}
\hline Expt. No. & A & B & C & D & $\begin{array}{c}\text { MRR } \\
\mathbf{g m . h r}^{-1}\end{array}$ & OC $(\boldsymbol{\mu m})$ \\
\hline 1 & 7 & 15 & 50 & 35 & 4.76 & 314 \\
\hline 2 & 7 & 25 & 65 & 38 & 4.86 & 216 \\
\hline 3 & 7 & 35 & 80 & 40 & 5.20 & 131 \\
\hline 4 & 9 & 15 & 65 & 40 & 5.22 & 162 \\
\hline 5 & 9 & 25 & 80 & 35 & 5.45 & 100 \\
\hline 6 & 9 & 35 & 50 & 38 & 5.98 & 143 \\
\hline 7 & 11 & 15 & 80 & 38 & 6.66 & 122 \\
\hline 8 & 11 & 25 & 50 & 40 & 6.72 & 132 \\
\hline 9 & 11 & 35 & 65 & 35 & 6.90 & 202 \\
\hline
\end{tabular}




\section{RESULTS AND DISCUSSION}

The ASTM standard specimen is imparted for the compressive load to determine the compressive strength of the specimen. The area of the specimen considered is $360 \mathrm{~mm}^{2}$ and the failure load is $10750 \mathrm{kgf}$. Hence the compressive strength is nothing but load by area, the calculated compressive strength of the specimen is $292.94 \mathrm{~N} . \mathrm{mm}^{-2}$.

The bending stress is nothing but $3 \mathrm{PA} / \mathrm{bd}^{2}$ where is the length of the specimen $(155 \mathrm{~mm}), \mathrm{b}$ is the breath of the specimen $(27 \mathrm{~mm})$, $d$ is the thickness $(10 \mathrm{~mm})$ and $P$ is the load at the failure $(60 \mathrm{kgf})$. The estimated bending stress of the specimen is $1.31 \mathrm{~N} \cdot \mathrm{mm}^{-2}$. The specimen is also subjected to Rockwell (B scale) testing and based on the testing the Rockwell hardness numbers is found to be $50 \mathrm{HRB}, 59 \mathrm{HRB}$, $54 \mathrm{HRB}$. The specimen had the highest hardness (59 HRB) due to the small size of its mixing ratio of $\mathrm{Mg}$ and $\mathrm{Gr}$ particles. The average grain size of the composite also contributed to its high hardness value since the grain boundaries acted as barriers for the propagation of dislocations. In Brinell hardness for impression diameters of $2.2 \mathrm{~mm}, 2.3 \mathrm{~mm}, 2.4 \mathrm{~mm}$ the Brinell hardness number is found to be $127.23 \mathrm{BHN}, 117.92 \mathrm{BHN}$, 109.89 BHN respectively as per the below mentioned Equation 1.

$$
B H N=\frac{\mathrm{P}}{\left(\frac{\pi \mathrm{D}}{2\left(\mathrm{D}-\sqrt{\mathrm{D}^{2}}-d^{2}\right)}\right)}
$$

The frictional force of $11.3 \mathrm{~N}$ (maximum) is obtained during wear test and impact strength of the specimen is calculated and it is found to be $\mathrm{J}^{-2}=0.4 \times 10^{5}$. Area of cross section of specimen $(\mathrm{A})=\mathrm{b} \times\left(\mathrm{d}-\mathrm{d}_{1}\right) \mathrm{mm}^{2}$.Impact strength $(\mathrm{I})=\mathrm{K} / \mathrm{A}$ $\left(\mathrm{J} . \mathrm{mm}^{-2}\right)$, Breath (b) $=10 \mathrm{~mm}$, Depth (d) $=10 \mathrm{~mm}$, Depth of notch $\left(d_{1}\right)=5 \mathrm{~mm}$, Impact energy $(K)=2 \mathrm{~J}$.

\section{MULTI-CRITERIA OPTIMIZATION}

\subsection{TOPSIS Method}

TOPSIS is a competent multi criteria decision making tool for solving complex problems. So multi objective optimization like TOPSIS method is used to overcome or ensure the result which obtained from the other techniques.

In this research original TOPSIS method is used and which is effective in solving multi criteria decision making problems. In TOPSIS method a multi-criteria optimization problem is thus converted into a single objective optimization problem using a combined approach. The normalized matrix, weighted normalized decision matrix, separation of alternatives from ideal and non ideal solutions and preference values for TOPSIS obtained for each experimental run with the ranking order are presented. The closeness co-efficient to the ideal solution and its highest rank is considered as the best value and performance measure for the process. The step-by-step procedure for TOPSIS is as follows [15].

Create the decision matrix consisting of $\mathrm{x}$ alternatives and $\mathrm{y}$ criteria, by using the Equation 2.

$$
\text { Decision Matrix }=\left[\begin{array}{cccc}
\lambda_{11} & \lambda_{12} & \ldots . . & \lambda_{1 y} \\
\lambda_{21} & \lambda_{22} & \ldots . & \lambda_{2 y} \\
\ldots . & \ldots . & \ldots . & \ldots . \\
\lambda_{x 1} & \lambda_{x 2} & \ldots . & \lambda_{x y}
\end{array}\right]
$$

Estimate the normalized decision matrix, the normalized value $\boldsymbol{\delta}_{\mathrm{ij}}$ is calculated by the Equation 3 .

$$
\begin{gathered}
\delta_{i j}=\frac{a_{i j}}{\sqrt{\sum_{j=1}^{m} a_{i j}^{2}}} \\
\mathrm{j}=1,2,3, \ldots \ldots \ldots ., \mathrm{x}, \mathrm{i}=1,2,3, \ldots \ldots \ldots \mathrm{y} .
\end{gathered}
$$

Calculate the weighted normalized decision matrix by using Equation 4.

$$
q_{i j}=\alpha_{i} \delta_{i j}
$$

$$
\mathrm{j}=1,2,3, \ldots \ldots, \mathrm{x}, \mathrm{i}=1,2,3, \ldots \ldots \ldots . \mathrm{y} .
$$

Find positive-ideal and negative-ideal solutions from the following expressions $5 \& 6$

$$
\begin{aligned}
& S^{+}=\left(q_{1}^{+}, q_{2}^{+}, \ldots . . . q_{y}^{+}\right) \text {for max values } \\
& S^{-}=\left(q_{1}^{-}, q_{2}^{-}, \ldots . ., q_{y}^{-}\right) \text {for min values }
\end{aligned}
$$

Obtain separation measures by using the following expressions $7 \& 8$.

$$
\begin{aligned}
& d_{j}^{+}=\sqrt{\sum_{i=1}^{n}\left(q_{i j}-q_{i}^{+}\right)^{2}} \\
& \mathrm{j}=1,2, \ldots \ldots . . \mathrm{x} . \\
& d_{j}^{-}=\sqrt{\sum_{i=1}^{n}\left(q_{i j}-q_{i}^{-}\right)^{2}}
\end{aligned}
$$

Calculate the relative closeness coefficient by using the following Equation 9.

$$
P_{i}=\frac{d_{j}^{-}}{d_{j}^{+}+d_{j}^{-}}
$$

The normalization values, weighted normalization values, separation measures and closeness coefficient values are listed in Table 3. In this study, equal priority is given to all the three responses. Based on the TOPSIS analysis the optimal combination for the higher MRR and lesser OC is $9 \mathrm{~V}, 25$ gm. $\mathrm{L}^{-1}, 80 \%$ duty cycle and $35^{\circ} \mathrm{C}$ electrolyte temperature $\left(\mathrm{A}_{2} \mathrm{~B}_{2} \mathrm{C}_{3} \mathrm{D}_{1}\right)$. 
Table 3. Preference value of responses

\begin{tabular}{|c|c|c|c|c|c|c|l|}
\hline \multicolumn{2}{|c|}{$\boldsymbol{\delta}_{\mathbf{i j}}$} & \multicolumn{2}{c|}{$\mathbf{q}_{\mathbf{i j}}$} & $\mathbf{S}^{+}$ & $\mathbf{S}^{-}$ & $\mathbf{P}_{\mathbf{i}}$ & Rank \\
\hline 0.2734 & 0.5809 & 0.1367 & 0.2904 & 0.1979 & 0.0615 & 0.2369 & 9 \\
\hline 0.2791 & 0.3996 & 0.1396 & 0.1998 & 0.1073 & 0.1079 & 0.5014 & 7 \\
\hline 0.2987 & 0.2423 & 0.1493 & 0.1212 & 0.0313 & 0.1762 & 0.8490 & 2 \\
\hline 0.2998 & 0.2997 & 0.1499 & 0.1498 & 0.0588 & 0.1486 & 0.7164 & 6 \\
\hline 0.3130 & 0.1850 & 0.1565 & 0.0925 & 0.0198 & 0.2023 & 0.9108 & 1 \\
\hline 0.3435 & 0.2645 & 0.1717 & 0.1323 & 0.0530 & 0.1604 & 0.7516 & 4 \\
\hline 0.3825 & 0.2257 & 0.1913 & 0.1128 & 0.0582 & 0.1777 & 0.7532 & 3 \\
\hline 0.3860 & 0.2442 & 0.1930 & 0.1221 & 0.0636 & 0.1684 & 0.7259 & 5 \\
\hline 0.3963 & 0.3737 & 0.1981 & 0.1868 & 0.1126 & 0.1036 & 0.4792 & 8 \\
\hline
\end{tabular}

\subsection{Mean Effect Plot}

The mean effect plot shown in Figure 1 shows the voltage at level 2, electrolyte concentration at level 2 , duty cycle at level 3 and electrolyte temperature at level 3. Based on mean effect Table 4 the optimal combination for the higher MRR and lesser $\mathrm{OC}$ is $9 \mathrm{~V}, 25 \mathrm{gm} \cdot \mathrm{L}^{-1}, 80 \%$ and $40^{\circ} \mathrm{C}$.

Table 4. Mean effect table

\begin{tabular}{|c|l|l|l|}
\hline Factors & Level 1 & Level 2 & Level 3 \\
\hline A & 0.5291 & 0.7929 & 0.6528 \\
\hline B & 0.5688 & 0.7127 & 0.3466 \\
\hline C & 0.5715 & 0.5656 & 0.8377 \\
\hline D & 0.5423 & 0.6687 & 0.7638 \\
\hline
\end{tabular}

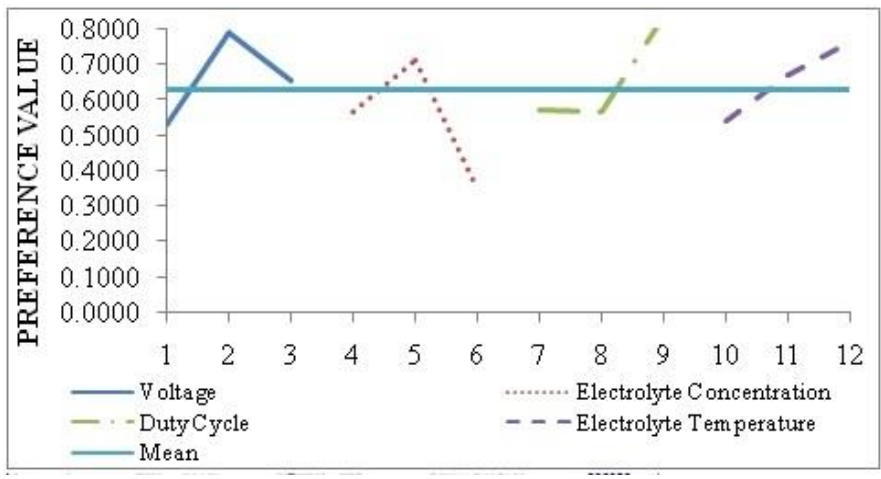

Figure 1. Mean effect Plot

\subsection{Characteristics of ANOVA}

ANOVA is a set of statistical method used by Ronald Fisher, a statistician and evolutionary biologist, to calculate the differences among group means and their related procedures. ANOVA test are useful for comparing three or more groups/ variables for statistical significance. Formulae for ANOVA is as follows[19]:

Total Sum of Squares $\left(\mathrm{SS}_{\mathrm{T}}\right)=\sum_{\mathrm{i}, \mathrm{j}=1}^{\mathrm{n}}\left(\mathrm{x}_{\mathrm{ij}}-\ddot{\mathrm{x}}\right)^{2}$

Sum of squares within groups $\left(\mathrm{SS}_{\mathrm{G}}\right)=\sum_{\mathrm{i}=1}^{\mathrm{n}}\left(\mathrm{x}_{\mathrm{i}}-\ddot{\mathrm{x}}\right)^{2}$

Error of sum of square $\left(\mathrm{SS}_{\mathrm{E}}\right)=\sum_{\mathrm{i}=1}^{\mathrm{n}}\left(\mathrm{x}_{\mathrm{ij}}-\overline{\overline{\mathrm{x}}}_{\mathrm{i}}\right)^{2}$

Therefore, $\mathrm{SS}_{\mathrm{T}}=\mathrm{SS}_{\mathrm{G}}+\mathrm{SS}_{\mathrm{E}}$

Mean square of standard deviations $(\mathrm{MS})=\frac{\mathrm{SS}}{\mathrm{DF}}$

Fisher Test value $=\frac{\mathrm{MS}_{\mathrm{G}}}{\mathrm{MS}_{\mathrm{E}}}$
Percentage of Contribution $=\frac{S S_{D}}{S S_{T}}$

Where, $\mathrm{MS}_{\mathrm{G}}=\frac{S S_{G}}{D F_{G}}, \mathrm{MS}_{\mathrm{E}}=\frac{S S_{E}}{D F_{E}}, \mathrm{DF}=$ Degree of Freedom,

$\mathrm{MS}_{\mathrm{G}}=$ Mean Square Error, $\mathrm{MS}_{\mathrm{E}}=$ Residual Error, $\mathrm{SS}_{\mathrm{D}}=\mathrm{Sum}$ of Square of deviations, $\mathrm{n}=$ No. of all individuals in experimental trails, $\mathrm{i}=$ No. of levels in experimental design, $\mathrm{j}$ $=$ No. of tests in experimental design, $\ddot{x}=$ Grand mean of SNR or $\mathrm{S} / \mathrm{N}$ ratio values $\mathrm{x}, x_{i j}=\mathrm{SNR}$ value of $\mathrm{i}^{\text {th }}$ level, $\mathrm{j}^{\text {th }}$ test, $x_{i}=$ SNR value of ith level, $\overline{\bar{x}}_{i}=$ Mean of SNR for $\mathrm{i}^{\text {th }}$ level

Moreover, the F-test named after fisher is also used to find out which factor have a major contribution on the performance characteristics [19]. Generally, the change of the process parameter has a notable effect on the performance measure when the F-value is large.

\section{EFFECT OF PROCESS PARAMETERS}

\subsection{Effect of voltage}

It is evident from the table 2 that higher voltage shows better MRR and OC. During higher voltage the current required for machining is more; moreover the electrolyte temperature improves the machining efficiency contributes for higher MRR. During the increase in electrolyte temperature the micro stirring effect dispels the debris from the machining zone resulting in lesser OC. Figure 2 shows the blind micro hole machined at $11 \mathrm{~V}, 15 \mathrm{gm} . \mathrm{L}^{-1}, 80 \%, 38^{\circ} \mathrm{C}$. It is clear from the SEM micrograph that profile of the blind micro hole is found to be circular.

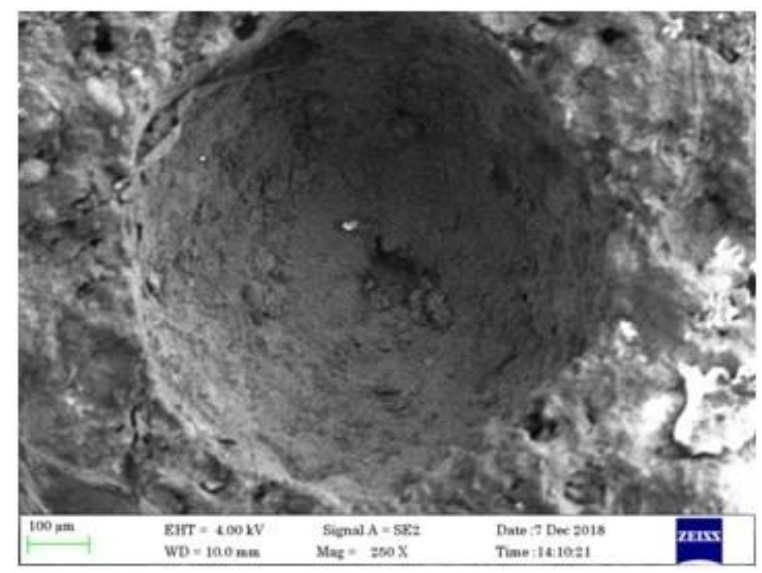

Figure 2. Circular micro-hole machined at $11 \mathrm{~V}, 15 \mathrm{gm} . \mathrm{L}^{-1}$, $80 \%$ and $38^{\circ} \mathrm{C}$

\subsection{Effect of electrolyte concentration}

The electrolyte concentration has significant effect on MRR and OC. The medium level of electrolyte concentration found to be suitable for higher MRR and lesser OC. Based on the mean effect plot the electrolyte concentration of $25 \mathrm{gm} . \mathrm{L}^{-1}$ is found to be suitable for better output performance. The lesser electrolyte concentration will have insufficient amount of ions required for machining, moreover higher electrolyte concentration supply more ions hence the amount of sludge formation reduces the machining efficiency. Figure 3 shows the over etched blind micro-hole machined at $7 \mathrm{~V}, 35 \mathrm{gm} \cdot \mathrm{L}^{-1}$, 
$80 \%$ and $40^{\circ} \mathrm{C}$. The sludge formation in between the inter electrode gap obstructs the current density required for machining and resulting in unstable machining. The distribution of current density causes the stray current effect on the workpiece. This stray current effect results in over etched surface on the workpiece. Moreover, the increase in temperature of the electrolyte improves the movement of ions in the electrolyte, contributing for higher MRR. The faster machining reaction due higher concentration and heating of electrolyte removes the wanted material from the workpiece resulting in over etched blind holes.

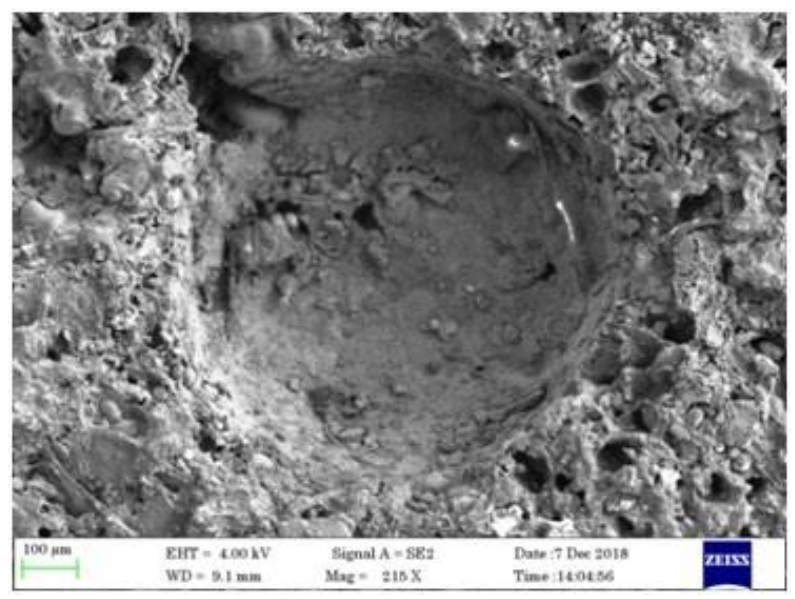

Figure 3. Over etched blind micro-hole machined at $7 \mathrm{~V}, 35$ gm. $\mathrm{L}^{-1}, 80 \%$ and $40^{\circ} \mathrm{C}$

\subsection{Effect of duty cycle}

The ratio of pulse on time to total time is called duty cycle and the machining is performed at $50 \mathrm{~Hz}$ and $1 \mathrm{~A}$ constant frequency and current respectively. Higher duty cycle shows higher MRR and lesser OC. At higher duty cycle the pulse time required for the machining is more which removes more materials for longer duration. Hence during higher pulse on time the more MRR takes and additionally the higher electrolyte temperature increase the concentration of the electrolyte. These increases in concentration make more ions available in the machining zone leading to higher machining efficiency. Figure 4 shows the blind micro-hole machined at $9 \mathrm{~V}, 25 \mathrm{gm} . \mathrm{L}^{-1}, 80 \%$ and $35^{\circ} \mathrm{C}$.

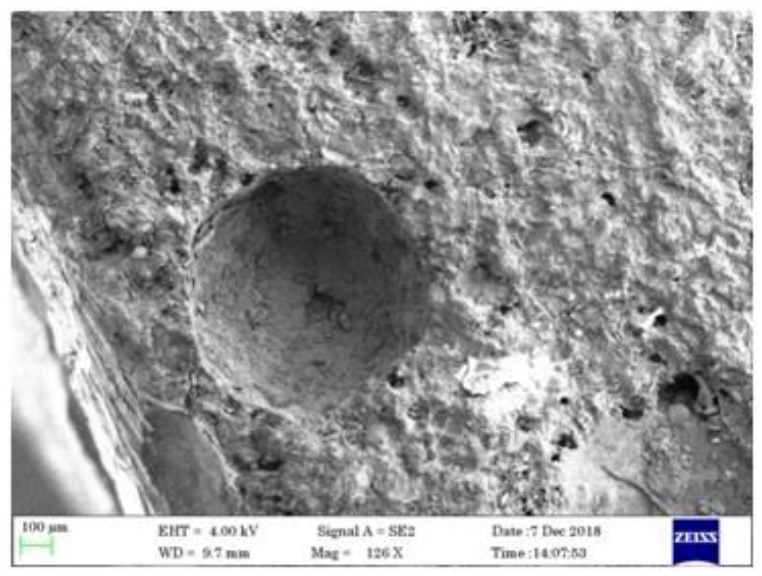

Figure 4. Blind micro-hole machined at $9 \mathrm{~V}, 25 \mathrm{gm} . \mathrm{L}^{-1}$, $80 \%$ and $35^{\circ} \mathrm{C}$

\section{ANALYSIS OF MACHINED SURFACE}

The fabricated work piece material is analyzed using energy dispersive X-ray spectroscopy (EDAX). The EDAX test is conducted on the blind hole and on the circumference of the blind micro-hole. Based on the Figure $5(\mathrm{a} \& \mathrm{~b})$, it is clear that there is equal distribution of reinforcement particles within the composites are observed. The EDAX confirms the presence oxides like silicon dioxide, aluminium oxide, calcium oxide and magnesium oxide. During micro ECM process the generation of oxides attribute for cluster of pits in the machining zone which is clearly noticed in the Figure 3. From the Figure $6(\mathrm{a} \& b)$, it is observed that other elements such as $\mathrm{Mn}, \mathrm{Fe}, \mathrm{Ni}$ and $\mathrm{Cu}$ are present in the matrix material.

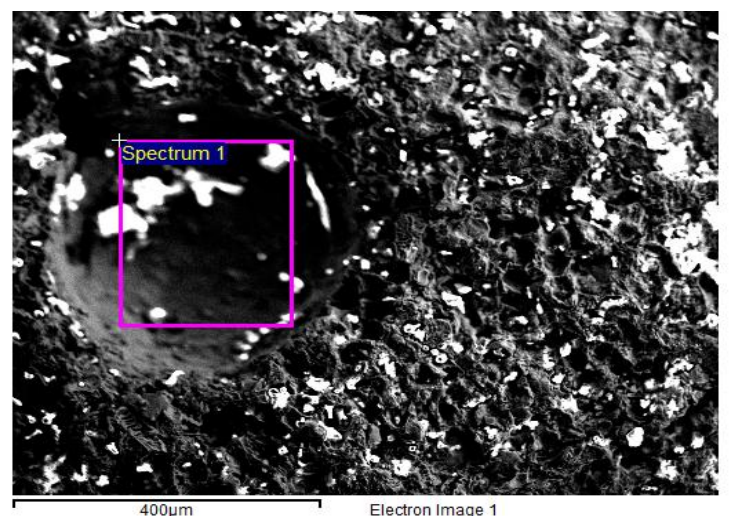

Figure 5(a). EDAX analysis on the micro-hole

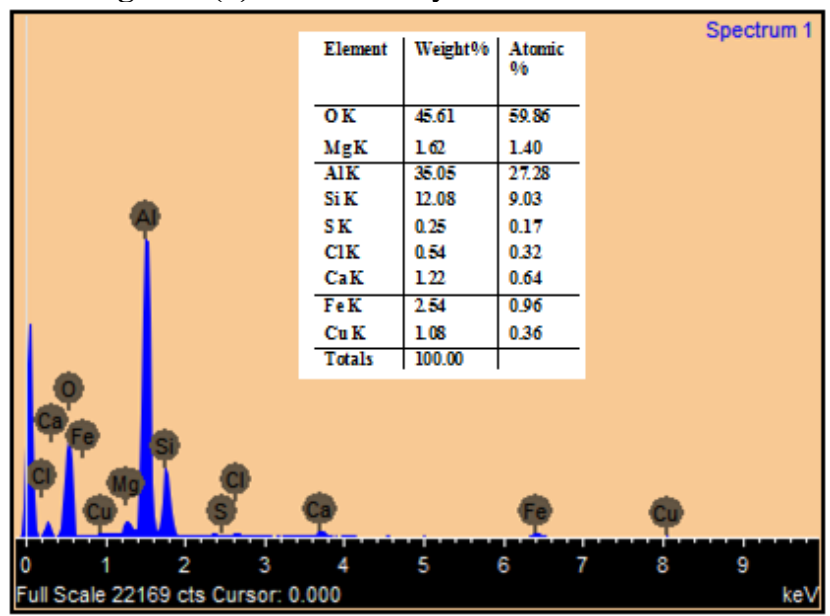

Figure 5 (b). Results of EDAX analysis

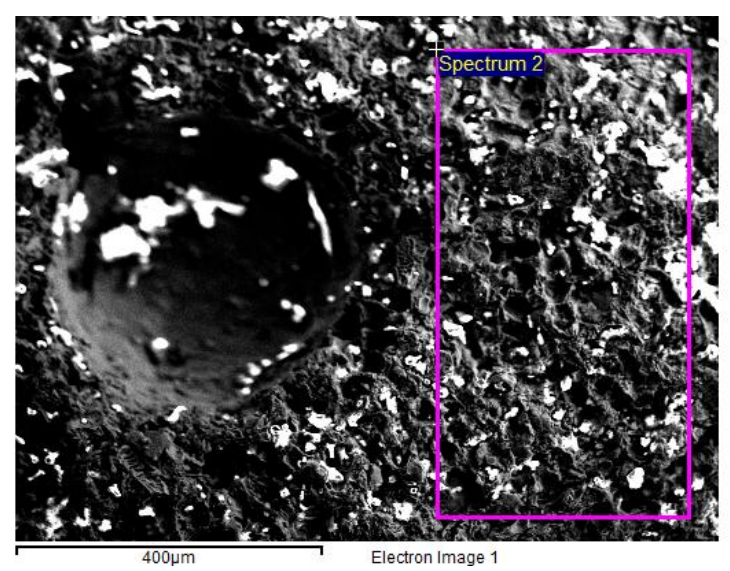

Figure 6(a). EDAX analysis on the outer region of the micro-hole 
Babu. B et al. / J. New Mat. Electrochem. Systems

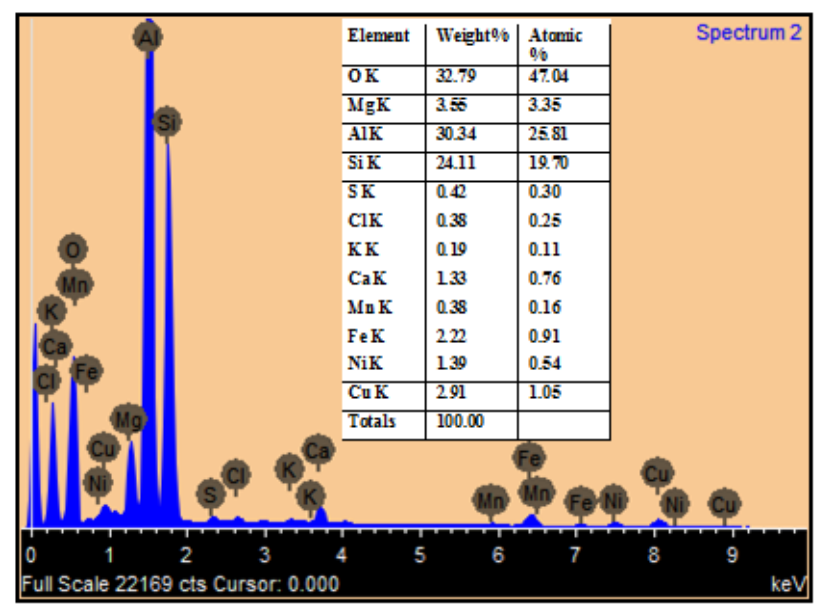

Figure 6(b). EDAX analysis results on the outer region of micro-hole

\section{ANALYSIS OF VARIANCE (ANOVA)}

The effect of individual factors on MRR and OC is analyzed using ANOVA. The machining parameters and its degrees of freedom are presented in the table 5. Each factor has three levels and the degrees of freedom are number of levels -1 and hence each factor has 2 degrees of freedom. The sum of the squares (SS) and mean sum of the squares (MS) are calculated and presented in the table. Higher the $\mathrm{F}$ values shows significant contribution and hence duty cycle shows 0.2533 which is of $40.24 \%$ compared to other parameters. Next contributing factors are voltage followed by electrolyte temperature. Electrolyte temperature shows $20.57 \%$ significant contribution among all factors.

Table 5. Parameters of the Analysis of Variance

\begin{tabular}{|c|r|r|r|r|c|}
\hline Symbol & DF & SS & MS & F & $\begin{array}{c}\text { \% } \\
\text { Contribution }\end{array}$ \\
\hline A & 2 & 0.1045 & 0.0523 & 0.1828 & 29.0345 \\
\hline B & 2 & 0.0366 & 0.0183 & 0.0639 & 10.1528 \\
\hline C & 2 & 0.1449 & 0.0724 & 0.2533 & 40.2413 \\
\hline D & 2 & 0.0741 & 0.0370 & 0.1295 & 20.5714 \\
\hline E & 1 & 0.2860 & 0.2860 & & 0.0000 \\
\hline & 9 & 0.6460 & 0.0718 & & 100 \\
\hline
\end{tabular}

\section{CONCLUSIONS}

1. Hybrid aluminium MMCs with $12 \%$ magnesium oxide $(\mathrm{MgO})$ and $5 \%$ graphite $(\mathrm{Gr})$ were fabricated and mechanical properties were studied. The compressive strength, bending stress frictional force, impact strength were found to be 292.94 N.mm ${ }^{-2}, 1.31$ N.mm², $11.3 \mathrm{~N}$ (maximum) $\mathrm{J} \mathrm{m}^{-2}=0.4 \times 10^{5}$ respectively.

2. The highest hardness value is obtained during Brinell and Rockwell testing 127.23 BHN, 59 HRB respectively.

3. Machinability testing using micro electrochemical machining (micro ECM) is performed on the hybrid AMMCs by varying the voltage, electrolyte concentration, duty cycle and electrolyte temperature.

4. $\mathrm{L}_{9} \mathrm{OA}$ is conducted and the experimental results are analyzed using the TOPSIS method. Based on the
TOPSIS analysis the optimal combination for the higher MRR and lesser OC is $9 \mathrm{~V}, 25 \mathrm{gm} . \mathrm{L}^{-1}, 80 \%$ duty cycle and $35^{\circ} \mathrm{C}$ electrolyte temperature (A2B2C3D1).

5. ANOVA shows that the duty cycle is the most significant factor followed by voltage and electrolyte temperature for higher material removal rate (MRR) and lower over cut (OC).

6. The experimental results obtained from TOPSIS and ANOVA shows that the electrical parameters such as higher level of duty cycle and medium level of voltage shows a significant contribution on the MRR and OC. Moreover electrolyte temperature shows $20.57 \%$ significant contribution among all factors.

7. Based on mean effect table the optimal combination for the higher MRR and lesser OC is $9 \mathrm{~V}, 25$ gm.L ${ }^{-1}, 80 \%$ and $40^{\circ} \mathrm{C}$.

8. The EDAX confirms the presence and significant distribution of major alloying elements like silicon, aluminium, calcium and magnesium. Moreover the oxides are formed after the micro-ECM process.

\section{REFERENCES}

[1] Reddy, P. S., Kesavan, R., \& Ramnath, B. V. (2018). Investigation of mechanical properties of aluminium 6061-silicon carbide, boron carbide metal matrix composite. Silicon, 10(2):495-502. https://doi.org/10.1007/s12633-016-9479-8.

[2] Inegbenebor, A. O., Bolu, C. A., Babalola, P. O., Inegbenebor, A. I., \& Fayomi, O. S. I. (2018). Aluminum silicon carbide particulate metal matrix composite development via stir casting processing. Silicon, 10(2): 343-347. https://doi.org/10.1007/s12633-016-9451-7.

[3] Arunachalam, R., Piya, S., Krishnan, P. K., Muraliraja, R., Christy, J. V., Mourad, A. H. I., \& Al-Maharbi, M. (2019). Optimization of stir-squeeze casting parameters for production of metal matrix composites using a hybrid analytical hierarchy process-Taguchi-Grey approach. Engineering Optimization, 118. https://doi.org/10.1080/0305215X.2019.163969.

[4] Narayan, S., \& Rajeshkannan, A. (2017). Hardness, tensile and impact behaviour of hot forged aluminium metal matrix composites. Journal of materials research and technology, 6(3): 213219https://doi.org/10.1016/j.jmrt.2016.09.006.

[5] Subbarao, E., \& Ramanaiah, N. (2016). Microstructure and Mechanical properties of Al-Mg-Si based metal matrix composites reinforced with B4C particles produced through Stir Casting processes. Journal of Production Engineering, 19(1): 75-80. https://doi.org/10.1016/j.jmrt.2016.09.006.

[6] Munisamy, B., Madhavan, V. R. B., Chinnadurai, E., \& Janardhanan, J. (2019). Prediction of mechanical properties of Al6061 metal matrix composites reinforced with zircon sand and boron carbide. Materials Testing, 61(6): 537-542. https://doi.org/10.3139/120.111337.

[7] Senthilkumar, C., \& Ganesan, G. (2018). Modeling of ECM process parameters. Materials Testing, 60(12): 1215-1220. https://doi.org/10.3139/120.111270.

[8] Uthayakumar, M., Kumaran, S. T., Khan, M. A., Skoczypiec, S., \& Bizon, W. (2020). Microdrilling of AA (6351)-SiC-B4C Composite Using Hybrid Micro- 
ECDM Process. Journal of Testing and Evaluation, 48(4). https://doi.org/10.1520/JTE20180216.

[9] Maniraj, S., \& Thanigaivelan, R. (2019). Effect of electrode heating on performance of electrochemical micromachining. Materials and Manufacturing Processes, 34(13):

14941501. doi: 10.1080/10426914.2019.1655153.

[10] Maniraj, S., \& Thanigaivelan, R. (2019). Optimization of Electrochemical Micromachining Process Parameters for Machining of AMCs with Different\% Compositions of GGBS Using Taguchi and TOPSIS Methods. Transactions of the Indian Institute of Metals, 72(12): 3057-3066. https://doi.org/10.1007/s12666-019-01772-3.

[11] Prakash, J., \& Gopalakannan, S. (2020). TeachingLearning-Based Optimization Coupled with Response Surface Methodology for Micro Electrochemical Machining of Aluminium Nanocomposite. Silicon, 1-24. https://doi.org/10.1007/s12633-020-00434.

[12] Satishkumar, P., Natarajan, N., Dharmalingam, S., \& Pitchandi, P. (2018). Investigation of mechanical, morphological studies and electrochemical micro holing process parameters on Al6061-SiC-Gr hybrid metal matrix composites. International Journal of Heavy Vehicle $\quad$ Systems, 25(3-4): 430-441. https://doi.org/10.1504/IJHVS.2018.094836.

[13] Hynes, N. R. J., \& Kumar, R. (2018). Electrochemical machining of aluminium metal matrix composites. Surface Engineering and Applied Electrochemistry, 54(4): 367-373 https://doi.org/10.3103/S1068375518040087.

[14] Jayaganthan, A., \& Prakash, K. S. (2018). Influence of machining parameters of electrochemical micromachining process over magnesium based hybrid metal matrix composite. Materials Research Express, 6(2): 026510. https://doi.org/10.1088/2053-1591/aae959

[15] Rajan, N., Thanigaivelan, R., \& Muthurajan, K. G. (2019). Machinability studies on an a17075 composite with varying amounts of $b_{4} c$ using an induction-heated electrolyte in electrochemical machining. Materiali In Tehnologije, 53(6): 873-880. doi:10.17222/mit.2019.077.

[16] Kalra, C. S., Kumar, V., \& Manna, A. (2018). Analysis of electrochemical behavior on micro-drilling of cast hybrid $\mathrm{Al} /\left(\mathrm{Al}_{2} \mathrm{O}_{3 \mathrm{p}}+\mathrm{SiC}_{\mathrm{p}}+\mathrm{C}_{\mathrm{p}}\right)-\mathrm{MMC}$ using micro-ECM process. Proceedings of the Institution of Mechanical Engineers, Part L: Journal of Materials: Design and $\begin{array}{ll}\text { Applications, } & \text { 232(1): 67-79. }\end{array}$ https://doi.org/10.1177/1464420715615907.

[17] Rajan, N., Thanigaivelan R.R., Muthurajan, K.G. (2018). Effect of electrochemical machining process parameters on anisotropic property of metal matrix composites A17075. Journal of New Materials for Electrochemical $\begin{array}{llll}\text { Systems, } & 21 & \text { (4): } & \text { 239-242. }\end{array}$ https://doi.org/10.14447/jnmes.v21i4.a08.

[18] Shanian, A., \& Savadogo, O. (2006). TOPSIS multiplecriteria decision support analysis for material selection of metallic bipolar plates for polymer electrolyte fuel cell. Journal of Power Sources, 159(2): 1095-1104. https://doi.org/10.1016/j.jpowsour.2005.12.092.

[19] Thanigaivelan, R., Arunachalam, R. M., Jerald, J., \& Niranjan, T. (2011). Applications of Taguchi technique with fuzzy logic to optimise an electrochemical micromachining process. International Journal of Experimental Design and Process Optimisation, 2(4): 283-298. https://doi.org/10.1504/IJEDPO.2011.04356. 